\title{
Diagnostic value of a combined C-reactive protein and haptoglobin test in new cases of upper tract urothelial carcinoma
}

\author{
Hossein Beig-Mohammadi ${ }^{1}$, Nahid Masoudian ${ }^{1}$, Ali Tabibi ${ }^{2}$, Abdolamir Allameh $^{3 *}$
}

1. Department of Biology, Faculty of Basic Science, Damghan Branch, Islamic Azad University, Damghan, Iran

2. Labbafinejed Hospital, Shaheed Beheshti University of Medical Sciences, Tehran, Iran

3. Department of Clinical Biochemistry, Faculty of Medical Sciences, Tarbiat Modares University, POB 14115-331, Tehran, Iran

*Corresponding author:Tel: +98 2182883877 Fax: +98 218006544

Address: Department of Clinical Biochemistry, Faculty of Medical Sciences, Tarbiat Modares University, POB 14115-331, Tehran, Iran

E-mail: allameha@modares.ac.ir

Received: 2015/11/15 revised: 2016/01/9 accented: 2016/02/19

\section{Abstract}

Introduction: Serum C-reactive protein (CRP) is believed to be increased in metastatic urothelial cancer of the bladder. However, the changes depend on the stage and grade of the upper tract urothelial carcinoma (UTUC). This study aimed to compare low-range and highrange serum CRP and haptoglobin in new cases of UTUC.

Materials and methods: Blood was collected from newly diagnosed patients with UTUC $(\mathrm{n}=43$ patients; 39 male/4 female) and normal individuals $(\mathrm{n}=26 ; 24$ male and 2 female) with no sign of infection or cancer. All the patients showed clinical symptoms of bladder cancer. Serum CRP and haptoglobin were estimated based on conventional methods.

Results: Haematuria and polyuria were common symptoms in $65.12 \%$ of the patients suffering from UTUC. The serum level of HAPT in control and UTUC patients was $126 \pm 13$ and $181 \pm 14.5 \mathrm{mg} / \mathrm{dl}$ respectively. No significant difference was observed in HAPT level in patients and controls. The HAPT was in the high-range level in $27 \%$ of controls and $30 \%$ of the patients. The average serum CRP level in patients and controls was $11.87 \pm 3.5 \mathrm{mg} / \mathrm{l}$ and $11.45 \pm 4.2 \mathrm{mg} / \mathrm{l}$, respectively. Serum CRP was above $3.5 \mathrm{mg} / 1$ (>3.5 mg/l) in $46 \%$ of patients (20/43). The CRP level was significantly higher $(\mathrm{P}=0.023)$ in patients having $\mathrm{CRP}$ above $3.5 \mathrm{mg} / \mathrm{l}$ compared to respective controls.

The UTUC patients were separated into two groups based on low-range $(<3.5 \mathrm{mg} / \mathrm{l})$ and highrange CRP ( $>3.5 \mathrm{mg} / \mathrm{l})$.Serum CRP was $<3.5 \mathrm{mg} / \mathrm{l}$ in $69 \%$ of the controls, whereas $31 \%$ of controls had CRP $>3.5 \mathrm{mg} / \mathrm{l}$. However, $46 \%$ of UTUC patients had serum CRP $>3.5 \mathrm{mg} / \mathrm{l}$ and $54 \%$ of UTUC patients had serum CRP $<3.5 \mathrm{mg} / \mathrm{l}$.

Conclusion: Although there was no difference in haptoglobin levels in patients and controls, but serum CRP was significantly increased in patients and it was associated with clinical symptoms of UTUC, suggesting that serum CRP can be considered as a complementary test for detection of low-grade UTUC.

Keywords: Bladder cancer, Biomarkers, CRP, Haptoglobin, Low-grade

\section{Introduction}

Urothelial carcinoma is the most common malignancy which develops in epithelium of bladder, ureter and kidney. Upper urinary tract urothelial carcinoma (UTUC) and bladder cancer is arising from the epithelial lining (i.e., the urothelium) of the urinary bladder. It is a disease in which abnormal cells multiply without control in the bladder $(1,2)$. 
Currently, the gold standard for diagnosis of bladder cancer is to receive biopsy during cystoscopy. In this procedure a visual detection by transurethral resection of bladder tumor (TURBT) is followed by transurethral surgery. Urine cytology is also used as an important diagnosis test with high specificity but low sensitivity for lowgrade bladder tumors (3). According to $\mathrm{Lu}$ et al., 2014, only $66.7 \%$ of UTUC patients show carcinoma cell in urine cytology (4). There are also other non-invasive urine bound markers available as aids in the distinction of bladder cancer, including human complement factor H-related protein, high-molecular-weight carcinoembryonic antigen (CEA), and nuclear matrix protein 22 (NMP22) and urinary bladder cancer antigen, CYFRA 21 1 and NMP22 $(3,5,6)$. Other non-invasive urine based tests include the CertNDx Bladder Cancer Assay, which combines mutation detection in fibroblast growth factor receptor-3 (FGFR3) with protein and DNA methylation markers to detect cancers across stage and grade, UroVysionTM for detection of aneuploidy of chromosome 3,7 and 17 and loss of 9p21 locus (7-9).

Interest has been reported in identification of reliable biochemical and tumor markers for diagnosis of upper tract urothelial carcinoma of bladder. In this line very recently $\mathrm{Lu}$ et al., 2015 (4) used immunological and proteomic analysis in urine sample to examine the potential value of selected markers in UTUC patients. In recent years it has been reported that serum CRP level is associated with survival of patients suffering from various cancers including; localized and metastatic renal cell carcinoma, upper urinary tract and penile cancers $(10,11)$.

The progression of UTUC is associated with systemic inflammation, but there are controversies over the inflammatory responses for prediction of cancer development. In this line, there are controversies over the use of serum Creactive protein (CRP) as an acute-phase reactant in diagnosis and progression of
URT. CRP is recognized as an infection and inflammatory index; however the association of CRP-related responses to UTUC malignancy requires further investigation.

The value of serum CRP in diagnosis of metastatic urothelial cancer cancers of the bladder has been investigated (12). This study suggests that the serum CRP value prior to regular treatment could be of prognostic significance in patients with metastatic urothelial cancer of the bladder. Likewise, Stein et al. (13), reported that the preoperative high levels of serum Creactive protein (CRP) is associated with locally advanced and metastatic UUT-UC. Haptoglobin is also an acute phase protein; the main function of this plasma protein is to bind to hemoglobin produced as a result of hemolysis. There are evidences which show that haptoglobin possess antioxidant activity and can contribute to the acute phase responses.

The association of serum total haptoglobin levels with the development of different types of malignancies in humans has been investigated. An association between alpha-1-antitrypsin and haptoglobin phenotype particularly type $2-2$ has been reported in bladder cancer patients (14). According to Kang et al. (15), the haptoglobin $\beta$-chain is elevated in patients suffering from lung cancer, suggesting that the haptoglobin $\beta$-chain can be used as a supportive biomarker for human lung cancers. Studies on the haptoglobin genotypes (polymorphism) in breast cancer patients in Jordan showed that the frequency of $\mathrm{Hp} 1$ and $\mathrm{Hp} 2$ allele is higher in non-familial breast cancer compared to that in familial breast cancer (15). More recently a report from Turkey by Pirinççi et al. (16), showed that serum haptoglobin levels increases in patients with bladder cancer compared to healthy controls. Moreover, it was demonstrated that the levels of haptoglobin protein increased with increasing tumor grades and were significantly higher in patients with metastatic disease and the presence of 
lymphovascular involvement, lymph node metastases and increasing tumor burden. It has also been demonstrated that elevated haptoglobin levels are associated with a higher stage, grade, and measure of distant metastasis and larger tumor size, suggesting that the elevated serum haptoglobin levels may provide a useful diagnostic and treatment biomarker for patients with bladder cancer.

Despite the studies using either CRP or haptoglobin as new biomarkers for diagnosis of bladder cancer, there are two issues to be addressed in the present casecontrol study. Firstly, the implication of CRP and/or haptoglobin in early detection of low-grade tumors of bladder cancer. This can be achieved by measuring these parameters in patients prior to systemic therapy. Secondly, the usefulness of a combined tests (CRP and haptoglobin) for early diagnosis of bladder cancer.

\section{Materials and methods}

Patients and sample collection: This casecontrol study was carried out on a group of patients with UTUC symptoms and a group controls. The patients referred to the hospital with urinary complications, such as polyuria, dysuria and hematuria. As shown in Table 1, the study population consist of patients $(n=43)$ and a control group with age-and sex match subjects $(n=26)$ who had no acute or chronic diseases.

Blood sample was collected by venepuncture from each patient after undergoing sonography and cystoscopy. After obtaining the demographic information of each individual, blood was collected; serum was separated and stored at freezer for biochemical assays.

The study protocol conforms to the ethical guidelines of the Declaration of Helsinki as reflected in the guidelines of the Medical Ethics Committee, Ministry of Health of Iran. Blood was collected from each subject after informed consent was given.

Measurement of serum CRP: Serum CRP was measured by nephelometric method using MININEPH ${ }^{\text {TM }}$ kit (The Binding Site
Group Ltd, Birmingham, UK). All the assays were carried out in duplicate and the results were presented as mean \pm SD.

Estimation of serum haptoglobin: Serum Haptoglobin was estimated by immunoturbidimetric assay using a commercially available kit; Tina-quant Haptoglobin ver.2 (Cobas Integra) purchased from Roche Diagnostics, Mannheim, Germany). In this assay human haptoglobin forms a precipitate with a specific antiserum which is determined at $340 \mathrm{~nm}$.

\section{Results}

In this study levels of CRP and total haptoglobin were measured in serum samples collected from patients diagnosed with bladder cancer (UTUC) based on cystoscopy. The patients were new cases prior to medical interference. Besides serum samples from normal individuals were used as control to compare the data.

As shown in Table 1, most of the cases were male and $55.81 \%$ of patients were smoking. More than $65 \%$ of patients (28/43) suffered from hematuria. As shown, all the 43 patients (100\%) underwent cystoscopy/sonography as part of diagnosis program and proved to be positive for this assay.

Table 1. Demographic information of in upper tract urothelial carcinoma patients and normal subjects.

\begin{tabular}{lcc}
\hline Characteristics & Controls & Patients \\
\hline Age (year) & $44-88$ & $25-86$ \\
Smoking & $9(34.61 \%)$ & $24(55.81 \%)$ \\
Hematuria & $0 \%$ & $28(65.12 \%)$ \\
Cystoscopy/Son & $0 \%$ & $43(100 \%)$ \\
ography & & \\
\hline
\end{tabular}

In this study serum CRP levels was categorized into two sub-groups (CRP $<3.5$ Vs CRP>3.5 mg/l). Based on this, serum CRP in approximately $50 \%$ of patients was above $3.5 \mathrm{mg} / \mathrm{l}(>3.5 \mathrm{mg} / \mathrm{l})$. The serum CRP levels was significantly higher $(\mathrm{P}<0.05)$ in patients with $\mathrm{CRP}>3.5$ compared to respective controls (CRP $>3.5 \mathrm{mg} / \mathrm{l}$ ). However CRP levels $>3.5 \mathrm{mg} / \mathrm{l}$ comprised about $30 \%$ of the control samples. Serum 
CRP levels in control samples was <3.5 $\mathrm{mg} / \mathrm{l}$ in about $70 \%(18 / 26)$ of control samples.

The samples were divided based on the haptoglobin level of less than $200 \mathrm{mg} / \mathrm{dl}$ and those having haptoglobin levels above 200 $\mathrm{mg} / \mathrm{dl}$. In normal samples, $73 \%$ (19/26) of samples showed haptoglobin between 50 to 200 , whereas $26.9 \%$ of the control samples showed haptoglobin levels between $<50$ to $>200 \mathrm{mg} / \mathrm{l}$.

In the cancer patients, about $70 \%$ of cases (30/43) showed low haptoglobin. Whereas, $30 \%(13 / 43)$ of cases showed high serum haptoglobin levels. The minimum level of haptoglobin in cancer patients was found to be $67.01 \mathrm{mg} / \mathrm{dl}$, whereas in controls minimum level was 13.79. Maximum serum haptoglobin in the patients and controls was 502.17 and $297.58 \mathrm{mg} / \mathrm{dl}$, respectively.

\section{Discussion}

Urinary biomarkers are often measured along with urine cytology for diagnosis and follow up of UTUC. However the sensitivity of these tests is low and may even be lower in low-grade tumors. There are many types of tumor markers the levels of which may be elevated and signify metastasis and recurrence of cancer of UTUC.

It has been suggested that serum-based tumor markers along with the urine cytology which is a specific test for bladder cancer can be used for low-grade tumors. There are evidences which show that inflammatory reactions which appear early before tumor formation play important role in predisposing epithelial cells to cancerous lesions and promotion of cancer. The inflammation and infectious conditions can trigger immune system and the release of immune mediators in circulation. The acute phase reactants (APRs) are released in response to such conditions. CRP and haptoglobin are among the APRs which are believed to change as a result of inflammatory responses such as cancerous lesions. However, the drawback of inflammatory mediators as biomarkers is their low specificity to a disease such as cancer. The use of a marker such as CRP in in combination with other markers has been suggested for diagnosis of cancers.

The parameters associated with inflammation can be used as complementary marker for cancer diagnosis particularly at advanced stages of tumorigenesis. Changes in serum total haptoglobin as well as its chains (alpha and beta) have been measured as patients suffering from UTUC cancer. The results of the present study clearly show that serum total haptoglobin is not significantly changes in new cases of UTUC subjects. These data may suggest that haptoglobin level remains within the normal range in new diagnosed patients and probably this marker is useful for measuring in patient with advance cancer and at metastatic stage. Haptoglobin changes may also be helpful marker if measured in terms of alpha/beta chains. Studies revealed that changes in expression of haptoglobin chains are promising for diagnosis of lung cancer (Kang et al., 2001). This finding is further confirmed by the report of Park et al.) by showing that secretion of alpha and beta chains of haptoglobin are significantly elevated in patients diagnosed with nonsmall cell lung carcinoma (NSCLC). The differences in total serum haptoglobin between control and bladder patient could even be more prominent if measured by more sensitive assays such as ELISA. According to Pirincci and co-workers), ELISA technique can help distinguish increased level of serum haptoglobin in patients with bladder cancer compared to healthy controls. Moreover, using ELISA technique it was reported that the levels of haptoglobin protein increased with increasing tumor gradesand were significantly higher in patients with metastatic disease and the presence of lymphovascular involvement, lymph node metastases and increasing tumor burden.

Serum CRP is often measured for diagnosis of diseases associated with chronic 
inflammation. In diagnostic laboratories, the serum level of CRP above 3.5 is considered abnormal for cases with inflammatory reactions. Currently, CRP is not a routine test for diagnosis of bladder cancer because there are controversies over the range of normal of serum CRP in research reports. Saito et al. (20), suggested the diagnostic value of serum CRP in terms of $\mathrm{CRP}<5$ and $\mathrm{CRP}>5$. However, a comparative analysis of these data showed that the detection limit of serum CRP $>3.5$ is reliable for discrimination between new cases of bladder cancer and normal samples.

The use of either of these tests alone or as a combined test for prediction of UTUC needs assay development considering sensitivity and specificity characteristics. It appears that these markers may be useful for distinguishing normal samples from patients at progression or metastasis stages. It is worth mentioning that development of cancer stages is associated with nonspecific reactions such as inflammation and infection. Hence, the elevated factors particularly CRP could be assigned to tumor-associated responses. This finding was further attested by showing that more

\section{References}

1. Li WM, Li CC, Ke HL, Wu WJ, Huang $\mathrm{CN}$, Huang $\mathrm{CH}$. The prognostic predictors of primary ureteral transitional cell carcinoma after radical nephroureterectomy. J Urol. 2009; 182(2): 451-8.

2. Oldbring J, Glifberg I, Mikulowski P, Hellsten $S$. Carcinoma of the renal pelvis and ureter following bladder carcinoma: frequency, risk factors and clinicopathological findings. $\mathrm{J}$ Urol. 1989; 141(6):1311-3.

3. Shariat S, Karam JA, Lotan Y, Karakiewizc PI. Critical evaluation of urinary markers for bladder cancer detection and monitoring. Rev Urol. 2008; 10 (2), 120-35. than $45 \%$ of UTUC patients had serum CRP levels above $3.5 \mathrm{mg} / \mathrm{l}$. In comparison about $70 \%$ of the control individuals had serum CRP $<3.5 \mathrm{mg} / \mathrm{l}$. Increased level of serum CRP was inconsistent with cystoscopy results and symptoms of bladder cancer.

When comparing the levels of serum total haptoglobin and CRP in terms of positive was beyond normal range in $26-30 \%$ of the samples both controls and patients. This data suggest that total serum haptoglobin has poor diagnostic value for low-grade UTUC. Nevertheless, increased serum levels of CRP above the normal range in approximately $50 \%$ of the bladder cancer patients may be promising as a biochemical diagnostic value in new cases of bladder cancer. Moreover, the kinetics of CRP release and the analysis of dynamic changes in CRP concentrations over time may be implicated in prediction of tumor aggressiveness and treatment efficacy of urological cancers (18)

In conclusion it appears that although there is no strong association between clinical signs and symptoms of UTUC and serum haptoglobin levels, serum CRP level has diagnostic potential as a complementary marker for early diagnosis of UTUC.

4. Lu CM, Lin JJ, Huang HH, KoYC, Hsu $\mathrm{L}$, Chen JC, et al. A panel of tumor markers, calreticulin, annexin A2, and annexin A3 in upper tract urothelialcarcinoma identified by proteomic and immunological analysis. BMC Cancer. 2014; 14(1): 363-73.

5. Washino S, Hirai M, Matsuzaki A, Kobayashi Y. Clinical usefulness of CEA, CA19-9, and CYFRA 21-1 as tumor markers for urothelial bladder carcinoma. Urol Int. 2011; 87(4):420-8.

6. Sanchez-Carbayo M, Urrutia M, Silva JM, Romani R, Gonzalez JM, De Buttrago JA, et al. Comparative predictive values of urinary cytology, urinary bladder cancer antigen, CYFRA 21-1 and NMP22 for evaluating 
symptomatic patients at risk for bladder cancer. J Urol. 2001; 165 (5):1462-7.

7. Halling KC, King W, Sokolova IA. A comparison of BTA stat, hemoglobin dipstick, telomerase and Vysis UroVysion assays for the detection of urothelial carcinoma in urine. $\mathrm{J}$ Urol. 2002; 167(5): 2001-6.

8. Moonen PM, Merkx GF, Peelen P, Karthaus HF, Smeet DF, Witjes JA. UroVysion compared with cytology and quantitative cytology in the surveillance of non-muscle-invasive bladder cancer. Eur Urol. 2007; 51(5):1275-80.

9. Bonberg N, Taeger D, Gawrych K, Johnen G, Banek S, Schwentner C, et al. Chromosomal instability and bladder cancer: the UroVysion(TM) test in the UroScreen study. BJU Int. 2013; 112(4):E372-82.

10. Steffens S, Kohler A, Rudolph R, Eggers H, Seidel C, Janssen M, et al. Validation of CRP as prognostic marker for renal cell carcinoma in a large series of patients. BMC Cancer. 2012; 12(1):399-404.

11. Steffens S, Al Ghazal A, Steinestel J, Lehmann R, Wegener G, Schnoeller TJ, et al. High CRP values predict poor survival in patients with penile cancer. BMC Cancer. 2013; 13:223-7.

12. Eggers H, Seidel C, Schrader AJ, Lehman R, Wegener G, Kuczyk MA, et al. Serum C-reactive protein: a prognostic factor in metastatic urothelial cancer of the bladder. Med Oncol, 2013; 30 (4) 705-10.

13. Stein B, Schrader AJ, Wegener G, Seidel C, Kuczyk MA, Steffens S. Preoperative serum C-reactive protein: a prognostic marker in patients with upper urinary tract urothelial carcinoma. BMC Cancer. 2013; 13:101.

14. Benkman HG, Hanssen HP, Ovenbeck R, Goedde HVV. Distribution of alpha1 antitrypsin and haptoglobin phenotypes in bladder cancer patients. Hum Hered, 1987; 37(5) 290-3.

15. Kang SM, Sung HJ, Ahn JM, Park JY, Lee SY, Park CS, et al. The haptoglobin beta-chain as a supportive biomarker for human lung cancers. Mol Biosys. 2011; 7(4) 1167-75.

16. Awadallah SM, Atoum MF. Haptoglobin polymorphism in breast cancer patients from Jordan. Clin Chim Acta, 2004; 341(1-2) 17-21.

17. Pirincci N, Gecit I, Gunes M, Kemik AS, Yuksel MB, Kaba M, et al. Haptoglobin levels in Turkish patients with bladder cancer and its association with clinicopathologicalfeatures. Asian Pac J Cancer Prev. 2012;13(12):6063-6.

18. Saito K, Kihara K. C-reactive protein as a biomarker for urological cancers. Nat Rev Urol. 2011; 8(12):659-66. 